\title{
El control interno en las Corporaciones Autónomas Regionales y el aseguramiento de la sostenibilidad con recursos fiscales
}

\section{Internal control in regional autonomous corporations and the assurance of sustainability, with fiscal resources}

\author{
Rocio Ariza Barajas \\ Angie Lucero Villamizar Vásquez \\ María Ana Martina Chía Suárez
}

\begin{abstract}
Resumen
Este artículo expone un análisis sobre el control interno en la autoridad ambiental, que en regiones específicas y departamentos de Colombia atañe a las Corporaciones Autónomas Regionales (CAR). Estas son responsables de la ejecución y control de la política ambiental para la sostenibilidad, por lo cual hacen uso de importantes recursos fiscales. Está basado en una revisión documental y una entrevista semiestructurada a un funcionario de la Contraloría General de la Nación. La urgencia de avanzar en la sostenibilidad ambiental ante los problemas que dificultan el bienestar futuro y el uso de un importante presupuesto reservado a la política ambiental, pero con carencia de herramientas idóneas para la medición de cambios ambientales y sus efectos socioeconómicos, resulta fundamental para analizar el control aplicado al manejo de recursos fiscales en el aseguramiento de la sostenibilidad ambiental, y con ello sentar bases para el uso eficiente de dineros de origen fiscal.
\end{abstract}

\section{Palabras clave}

Medio ambiente, gestión ambiental, gestión de recursos.

\section{Códigos de clasificación JEL: H61, M0, M41, Q52.}

\begin{abstract}
This article exposes an analysis on internal control in the environmental authority, which in specific regions and departments of Colombia, concerns the Regional Autonomous Corporations (CARs). responsible for the execution and control of the environmental policy for sustainability in what they make use of important fiscal resources. This is based on a documentary review and a semi-structured interview with an official of the National Comptroller's Office. The urgency of advancing environmental sustainability, given the problems that hinder future well-being and, the use of an important budget reserved for environmental policy, but lacking suitable tools for measuring environmental changes and their socioeconomic effects, is attractive to analyze the control applied to the management of fiscal resources in the assurance of environmental sustainability and, lay the foundations for the efficient use of monies of fiscal origin.
\end{abstract}

\section{Keywords}

Environment, environmental management, resource management.

1 Universidad Santo Tomás Bucaramanga. Correo electrónico: rocioarizabarajas@gmail.com Código ORCID: 0000-0003-4703-8607

2 Universidad Santo Tomás Bucaramanga. Correo electrónico: angievillamizzzar@gmail.com Código ORCID: 0000-0002-2891-4205

3 Universidad Santo Tomás Bucaramanga. Correo electrónico: mariana-chia@hotmail.com Código ORCID: 0000-0003-2845-7056 


\section{Introducción}

En Colombia se ha buscado propiciar condiciones para un desarrollo sostenible. Este propósito ha estado motivado por los acuerdos internacionales, que están basados en procurar condiciones favorables para un futuro mejor (García, 2011). Así, se han orientado las políticas del Estado hacia el mejoramiento de las dimensiones del desarrollo mediante sustanciales recursos fiscales que, en particular en la dimensión ambiental, se hacen difíciles de evidenciar. Por ejemplo, aspectos como la eficiencia de la destinación presupuestal no es del todo clara, debido a que se carece de sistemas de información idóneos que permitan hacer seguimiento a la ejecución de la política ambiental. En consecuencia, desde un análisis crítico, como importante tema de reflexión, se estudia el proceso de control interno (CI), como eje de aseguramiento del buen uso de recursos fiscales por la autoridad ambiental para viabilizar la sostenibilidad ambiental y así avanzar en un modelo sostenible de desarrollo.

De este modo, para llevar a cabo un estudio que permita reconocer el éxito de la gestión de las Corporaciones Autónomas Regionales (CAR) se enfatizó sobre el CI en estas y, a su vez, en la identificación, cuantificación y destinación de los impuestos y tasas ambientales, para establecer así los aciertos o deficiencias en los procesos de control, como base para redireccionar los procedimientos como mecanismos de un control eficiente.

Se expone el deber ser del CI y uso de los recursos fiscales en la sostenibilidad ambiental, que al confrontarlo con la realidad permita nuevos lineamientos para mejorar los procedimientos y herramientas para el $\mathrm{CI}$, de manera que se logre avanzar en la sostenibilidad en el marco del desarrollo con la garantía de un buen uso de recursos financieros del Estado, asumiendo como caso el CI y gestión de la Corporación Autónoma Regional para la Defensa de la Meseta de Bucaramanga (CDMB), con centro administrativo en Bucaramanga y operaciones en la provincia de Soto Norte del departamento de Santander.

\section{Diseño Metodológico}

Es un estudio de reflexión, de corte cualitativo que se fundamentó en una revisión bibliográfica, análisis documental y datos estadísticos de la Corporación Autónoma Regional para la Defensa de la Meseta de Bucaramanga CDMB sobre control interno y de información del Ministerio de Ambiente y Desarrollo. Se complementó con una entrevista semiestructurada a un funcionario de la Contraloría General de la Nación, en Bucaramanga, en la que se tuvieron en consideración cuatro ejes temáticos: control interno en las CAR, política fiscal en Colombia; aportes de las CAR a la sostenibilidad del territorio y situación actual de la CDMB. La información obtenida se organizó en tres categorías de análisis sobre los que se desarrolla el artículo. 
- Referentes en torno al aseguramiento de la sostenibilidad con recursos fiscales en las autoridades ambientales.

- Análisis situacional sobre el control interno en la autoridad ambiental frente a la sostenibilidad CAR con énfasis en el AMB.

- Cómo asegurar la sostenibilidad ambiental con recursos fiscales, a manera de estrategia.

\section{Referentes en el aseguramiento de la sostenibilidad con recursos fiscales en la autoridad ambiental}

\section{La sostenibilidad y el desarrollo nacional}

Cuando se habla de desarrollo se hace hincapié en la manera en que los seres humanos se adaptan a las condiciones del territorio, la región o, en general, del devenir de diversas situaciones (en cuanto a la idea de adaptación, múltiples han sido las formas de entenderla). Así, se consideraba la transformación de los bienes y recursos naturales como una práctica propia de la supervivencia, no obstante, actualmente, la transformación y explotación de los medios naturales se lleva a cabo bajo una lógica de consumismo, de acumulación de bienes y de servicios. En esta lógica, prima el bien individual sobre el bien común, lo que ha conllevado que emerjan diferentes procesos abióticos producto de la contaminación, perjudicando el ambiente, tanto de seres humanos como de sus procesos económicos y sociales, al igual que el de todos los seres que habitan el planeta, disminuyendo con ello la calidad de vida (Gudynas, 2009).

En dicho contexto emerge el concepto de responsabilidad social como el principal eje de acción y de mitigación. Este se encuentra orientado a un modelo de sostenibilidad, en el que es necesario que toda consecuencia producto de la actividad humana tienda a ser evitada o corregida y se proporcione estabilidad entre lo económico, lo ambiental y lo social, sin que prime uno de estos. Y también, donde figure el cambio de actitudes como eje principal de acción en la conservación de los recursos de la naturaleza y el ambiente para una responsable convivencia y se propicie el desarrollo de la nación (Mantilla, Cabeza y Vargas, 2015).

Por consiguiente, la responsabilidad social debe ser compartida en conjunto con la sociedad civil (demandante de los servicios), organizaciones y empresas (quienes ofrecen los servicios), en las que los impactos negativos (sociales y ambientales), producto de las actividades que se desarrollan, se supriman paulatinamente y se promuevan modos de producción en los que la prioridad corresponda a la retribución y mitigación de los impactos causados (Vallaeys, 2012). Igualmente, es clave tener en cuenta que la conjunción de políticas, instituciones, procedimientos, herramientas e información hace posible la participación de un espectro mayor de actores sociales (sean públicos o 
privados) en el manejo de conflictos, construcción y toma de decisiones, aceptando la responsabilidad social como una iniciativa de cambio (Brenner, 2010).

\section{Las políticas de Estado para la sostenibilidad ambiental}

Las actividades de la economía colombiana están demarcadas por la producción agropecuaria y por la explotación de minerales, debido a la naturaleza de estas prácticas, las afectaciones al medio ambiente por la explotación de los recursos naturales son considerables, lo que ha ayudado a los incrementos de la deforestación y la pérdida de la biodiversidad del país. Esta crisis ambiental está demarcada por ciertos factores, como la falta de un sistema de control en torno al uso y acceso a los recursos naturales, la falta de inversión social y de acompañamiento estatal y la falta de información a la población sobre los procedimientos que se realizan (De Castro, Cruz y Ruiz, 2009; Giraldo, 2013).

Ahora, en apartes la Constitución Política de Colombia de 1991 asociados a la sostenibilidad (arts. 79, 80, 95), se establece la necesidad de mantener un equilibrio entre lo económico, lo social y lo ambiental, con el fin de lograr una mejoría en las condiciones actuales para favorecer así un bienestar para los ciudadanos, en el que primen un ambiente sano y la participación comunitaria. Es así como surgen las políticas de Estado como eje de acción de la sostenibilidad en el que prima el bien común, independientemente de la ideología del gobierno de turno, donde se debe tener en cuenta el envejecimiento de la población, el déficit público, los diagnósticos e investigaciones en torno a las necesidades sociales y la inclusión de grupos vulnerables (Asamblea Nacional Constituyente, 1991; De Castro, Cruz y Ruiz, 2009).

Igualmente, en el artículo 334 de la Constitución Política de 1991, se estipula que el Estado es el garante en la explotación de los recursos naturales, en el uso del suelo, en la producción, distribución, utilización y consumo de los bienes, en el que el gasto público social será prioritario (Asamblea Nacional Constituyente, 1991).

\section{Gestión y control de los recursos fiscales de política ambiental}

Los recursos fiscales son agregados económicos y monetarios que se dan desde diferentes aportes de particulares para fines públicos. El recaudo es efectuado por parte del Estado y proviene de impuestos, derechos y aprovechamientos; el recaudo de impuestos es el mecanismo que otorga la mayor parte de los recursos fiscales de que dispone el Estado para su erogación. Los impuestos se componen, entre otros, del impuesto a la renta, impuesto sobre el valor añadido (IVA), impuestos antitécnicos e impuestos al patrimonio (García-Herrera, Torrejón, Alonso y Del Blanco, 2010).

La política fiscal se entiende como el conjunto de instrumentos y medidas que toma el Estado con el objeto de recaudar los ingresos necesarios para realizar las funciones que le ayuden a cumplir los objetivos de la política económica general. En este sentido, la política fiscal como herramienta del gobierno, le obliga a ejercer 
una gestión de las finanzas públicas, basada en el equilibrio entre lo recaudado por impuestos y otros conceptos y los gastos gubernamentales (López, 2012).

Debido a la crisis ambiental y a los constantes desastres naturales que acontecen como producto de esta situación, se han implementado controles sobre los procesos de produccion y extracción, en los que se reconoce a la naturaleza como un recurso agotable. Por ende, es necesario que en la implementación de dicha política ambiental, figure un conjunto de objetivos, principios, criterios y orientaciones para la protección de la naturaleza y el ambiente, en el aseguramiento de condiciones de vida de manera generacional (Niño, 2017).

En Colombia se ha llevado a cabo una transformación en materia de instrumentos de política, del manejo institucional ambiental y de los activos y bienes naturales renovables, incorporando instrumentos económicos de política ambiental, en la que se estipula una serie de entidades gubernamentales que ejecutan y controlan las retribuciones fiscales en torno a las politicas ambientales.

Desde 1972 se establecen tasas de retribución, como política para financiar acciones de la autoridad ambiental, estipuladas en el Código Nacional de Recursos Naturales Renovables y de Protección al medio ambiente bajo el Decreto 2811 de 1974, que con la Ley 99 de 1993 toman vigencia; es obligatoria y debe ser recaudada por la utilización directa e indirecta de la atmósfera, agua y suelo, aplicada por contaminación causada dentro de los límites permisibles (Niño, 2017; Muñoz, 2002; Villegas, Castiblanco, Berrout y Vidal, 2006).

Continuando, es importante comprender la diferencia entre tasa e impuesto: la Corte Constitucional en la Sentencia C-465 de 1993, expresa que las tasas son aquellos ingresos tributarios establecidos por el Estado, exigibles en el caso de que el particular decida utilizar un servicio público correspondiente al concepto de la tasa, por lo tanto, es la recuperación total o parcial de los costos que genera la prestación de un servicio, es una retribución equitativa por un gasto público que el Estado trata de compensar (Corte Constitucional, 1993; Villegas et al., 2006).

La ley también incorpora las tasas compensatorias y de uso, aprovechamiento forestal, sobretasa a los peajes, transferencias del sector eléctrico, además de imponer licencias, sanciones y permisos para el pago de gastos de protección y renovación del recurso y, además, establece la tasa contributiva fijada por la autoridad administrativa (CAR) (Correa, de la Ossa y Vallejo, 2007; Molina y Rivas, 2017; Vélez, 2005), así como la introducción en las últimas reformas tributarias de impuestos ambientales (impuesto al carbono e impuesto a las bolsas plásticas), descuentos y exenciones tributarias.

\section{Las CAR como entes reguladores en Colombia}

Las Corporaciones Autónomas Regionales y de Desarrollo Sostenible (CAR) son entes corporativos de carácter público, creados por la Ley 3a de 1961 y reguladas 
desde la Ley 99 de 1993 e incorporadas al Sistema Nacional Ambiental (SINA), el cual "responsabilizó directamente a las corporaciones de la gestión ambiental y, para trabajar de manera coordinada con las entidades territoriales en la ejecución de planes, programas y proyectos diseñados al respecto, comprometiéndose a hacer un seguimiento y control en cada región" (CAR, 2018).

Las CAR son entidades territoriales que se encargan de administrar los recursos renovables y del medio ambiente, igualmente tienden a establecer un ambiente óptimo para el desarrollo sostenible, conforme está establecido legalmente y según se ha expuesto por el Ministerio del Medio Ambiente y Desarrollo. Estas se caracterizan por estar constituidas geográficamente por un "mismo ecosistema o conforman una unidad geopolítica, biogeográfica o hidrogeográfica, dotados de autonomía administrativa y financiera, patrimonio propio y personería jurídica” (CAR, 2018).

Las CAR tienen una jurisdicción de 1.800 .000 hectáreas, con una población de 7.300 .000 de habitantes y están compuestas por la asamblea corporativa, que se encarga de la dirección y está integrada por representantes legales de las entidades territoriales de su competencia. Estos eligen al consejo directivo, del cual escogen un revisor fiscal o auditor interno; dicho consejo directivo está conformado por los gobernadores de los departamentos en los que haya jurisdicción de las CAR. También, el director general, que tiene una designación por periodo de tres años y ejerce su labor como representante legal de la corporación (Lacouture, 2006).

Dentro de las funciones de las CAR se tienen:

- Planificación Ambiental Regional: se realiza respecto a las prioridades de la región y al impacto que se genera en los contextos sociales, ambientales y económicos, dando prioridad a una gestión más coordinada, eficiente, transparente y participativa y en la cual se definen "instrumentos de seguimiento y evaluación de la gestión institucional y ambiental que permitirán establecer mediciones sobre su desarrollo" (Ministerio de Ambiente, 2019).

- Educación ambiental: es pieza clave para la prevención de efectos ambientales en los que se fortalezcan los procesos participativos y el afianzamiento de una cultura regional responsable de los procesos y del manejo de los recursos naturales, igualmente debe priorizar en sus acciones asesorar y brindar apoyo a las instituciones educativas de la región respecto a temas medio ambientales de la región (Lacouture, 2006).

- Asesoría: las CAR deben brindar asesoría a los entes territoriales en temas de desarrollo respecto a la formulación de planes y proyectos de índole ambiental que usen recursos provenientes del Fondo Nacional de Regalías; igualmente deben ofrecer orientación a programas de educación formal y no formal (Lacouture, 2006). 
- Gestión de la información ambiental: el Sistema de Información Ambiental para Colombia (SIAC) es un instrumento que permite que el Estado reconozca los recursos naturales que posee la nación e igualmente se evidencie el crecimiento del país, esto con el fin de documentar la información de aspectos locales y regionales y del impacto que las actividades regionales han causado al medio ambiente, en el cual las CAR permite su cumplimiento mediante tres indicadores: indicadores del desarrollo sostenible, indicadores ambientales y los indicadores de gestión, en los que se evalúe el cumplimento de estas respecto a las metas nacionales (Lacouture, 2006).

Tasas e impuestos ambientales manejadas por las CAR:

Tasa retributiva por vertimientos puntuales al agua: Buscan mejorar la calidad del recurso hídrico, el cual se ha visto perjudicado por la recepción directa o indirecta de vertimientos puntuales, con ello invertir en los sistemas de tratamiento de aguas residuales. Estas tasas se rigen por el artículo 42 de la Ley 99 de 1993, el Decreto 2667 de 2012 y el artículo 2.2.9.7.1.1. del Decreto Único Reglamentario 1076 de 2015 (Lacouture, 2006).

El recaudo de esta tasa tiene como destinación la creación de proyectos de inversión para la descontaminación hídrica y monitoreo de la calidad del agua, al igual que el cubrimiento de gastos para la implementación y seguimiento de la tasa por parte de la autoridad ambiental competente, de la cual podrá utilizar hasta el 10\% de los recursos recaudados de la tasa retributiva. Para lo anterior, las autoridades ambientales competentes deberán realizar la distribución en su presupuesto de ingresos y gastos a los que haya lugar para garantizar la destinación específica de la tasa (Correa, de la Ossa y Vallejo, 2007).

Tasa por utilización del agua: esta tasa es producto del cobro a los usuarios (personas naturales o jurídicas) por el uso del agua de una fuente natural, en virtud de un beneplácito de aguas (Ministerio de Ambiente, 2019). Igualmente, tiene como objetivo la protección y renovación de los recursos hídricos y fue reglamentada por el artículo 43 de la Ley 99 de 1993 y el artículo 2.2.9.6.1.1. del Decreto Único Reglamentario 1076 de 2015. La destinación de lo recaudado tiene como principal propósito: 1. elaborar un plan de ordenamiento y manejo de las cuencas hídricas; 2. realizar actividades de monitoreo, protección y recuperación del recurso hídrico en las diferentes cuencas identificadas en la geografía nacional (Ministerio de Ambiente, 2019; Muñoz, 2002).

Tasa Compensatoria por Aprovechamiento Forestal Maderable en Bosque Natural:

Es un tributo ambiental, por el acceso al servicio ecosistémico de aprovisionamiento de madera proveniente de los bosques naturales, bienes del Estado, definido como renta propia de las Autoridades Ambientales Competentes por medio del artículo 46 de la Ley 99 de 1993" (Ministerio de Ambiente, 2019). 
Esta tasa tiene como fin el manejo sostenible de los ecosistemas forestales y destinará los recaudos a la protección y renovación de los recursos naturales (Rodríguez y Ávila, 2014).

Transferencias del Sector Eléctrico (impuesto): este impuesto busca la protección del ambiente y la defensa de la cuenca hidrográfica, producto de la generación de energía hidroeléctrica y termoeléctrica. Está destinado a toda empresa generadora de energía hidroeléctrica o termoeléctrica cuya potencia nominal instalada total supere los 10.000 kilovatios. A su vez, está regulado por el artículo 45 de la Ley 99 de 1993, reglamentado por el Decreto Nacional 1933 de 1994, modificado transitoriamente por el Decreto Nacional 4629 de 2010, Modificado por el artículo 222, la Ley 1450 de 2011 y el artículo 2.2.9.2.1.1. Decreto Único Reglamentario 1076 de 2015 (Vélez, 2005).

Respecto a la recaudación y distribución del impuesto se estipula que:

[...] el 6\% de las ventas brutas de energía hidroeléctrica por generación propia del recaudo se transfiere el 3\% a las CAR para que se destine a la Protección del medio ambiente para la defensa de la cuenca hidrográfica y del área de influencia del proyecto. Del $4 \%$ de las ventas brutas de energía termoeléctrica por generación propia del recaudo se transfiere el $2.5 \%$ para la CAR, para protección ambiental del área donde está ubicada la planta. Del valor transferido, la CAR solamente podrá destinar hasta el $10 \%$ para gastos de funcionamiento (Viloria, 2010, p. 14).

Tasa Compensatoria por Caza de Fauna Silvestre: esta tasa tiene como fin, en primer lugar, preservar la fauna salvaje de las regiones de Colombia, a través de actividades de implementación y formulación de programas de conservación de la vida salvaje del país; igualmente del uso sostenible de las especies silvestres y, también, la repoblación de especies en vías de extinción; estas tasas se cobran a aquellas personas que utilizan la fauna salvaje para el control, la subsistencia, de manera deportiva y la zoo cría, en las que se tienen en cuenta tanto el proceso sancionatorio como eje de control y mitigación, como el tipo de caza, la nacionalidad, las características de la especie, su nivel de amenaza, estado del hábitat y número de especímenes cazados, entre otros aspectos.

De igual manera, dicha tasa está regulada por el artículo 42 de la Ley 99 de 1993 modificado por el artículo 211, Ley 1450 de 2011, adicionado al Decreto Nacional 1272 de 2016 y Decreto 1076 de 2015 y es de aclarar que esta tasa no sustituye las restricciones nacionales sobre cuidado y protección de especies autóctonas de cada región (Ministerio de Ambiente, 2016; Muñoz, 2002).

Sobretasa ambiental: es considerada como un impuesto ligado al impuesto predial que cobran las autoridades locales bajo unas tarifas fijadas por cada una de ellas; bajo unas limitaciones fijadas en la legislación colombiana, el porcentaje destinado al medio ambiente no puede ser inferior a $15 \%$ o superior al $25,9 \%$; la sobretasa deberá estar en el rango entre el 1,5 por mil y el 2,5 por mil sobre el avalúo de los bienes que sirven de base para liquidar el impuesto predial (Jaramillo y Villa, 2003). 


\section{Análisis situacional respecto al control interno - CI para salvaguardar los recursos fiscales de sostenibilidad ambiental}

Las empresas y organizaciones son sistemas abiertos que interactúan con el medio en el que se desenvuelven sus operaciones, en las que la oferta y la demanda se ve demarcada por las necesidades de la sociedad, donde los procesos y operaciones circunscriben ante la relación y la explotación de los recursos naturales; esta relación depende de la afectación que tenga en el medio ambiente, aunque el objetivo de la empresa radique en establecer una relación beneficiosa con el medio y con sus actividades, pero que "en ocasiones puede ser nociva y además conlleva una tendencia a informar de los aspectos favorables y obviar los desfavorables" (Castromán y Porto, 2005, p. 87).

No obstante, la sociedad cada vez es más rigurosa con los procedimientos que realizan los sectores económicos del país y por esto exigen información clara y concisa sobre la gestión y explotación de los recursos naturales (Luna, 2017; Viloria, 2005).

De este modo, es el CI toma especial importancia, como un proceso de cumplimiento que se lleva a cabo desde el consejo directivo, la administración u otro personal de una organización o empresa y es

diseñado para proveer seguridad razonable en relación con el logro de los objetivos relativos a la eficiencia y eficacia de las operaciones, a la confiabilidad de la información (financiera y no financiera) y al cumplimiento de leyes y regulaciones (Mantilla, 2018, p. 4).

El CI, como herramienta de gestión empresarial y organizacional, se estructuró partiendo de la necesidad de vigilar y verificar los objetivos propuestos, por lo tanto, "el CI en las organizaciones surge como una necesidad para apoyar el logro de los objetivos fijados por la alta gerencia y se ha convertido en un factor de vital importancia para todo tipo de organización a nivel mundial" (Vásquez, 2016, p. 144).

A continuación, en la figura 1 se presentan los objetivos que se persiguen en la gestión empresarial y organizacional, así como los objetivos que se persiguen con el control interno, como herramienta de función específica en el aseguramiento de información hacia el buen uso de recursos.

El CI se caracteriza por ser comparable, medible; en el que detectan desviaciones y que posteriormente se aplican o establecen medidas correctivas para mejorar las condiciones de la empresa u organización en la cual se pueden definir ciertos componentes que benefician o dificultan la ejecución y el desarrollo del CI; en el que radican elementos de equilibrio, de oportunidades, de establecimiento de objetivos en el que se fundamente el control como un medio para conseguir metas, variaciones, costos, excepción y funciones de vigilancia (García, 2014) tabla. 
Figura 1. Objetivos de gestión empresarial y organizacional, y de control interno

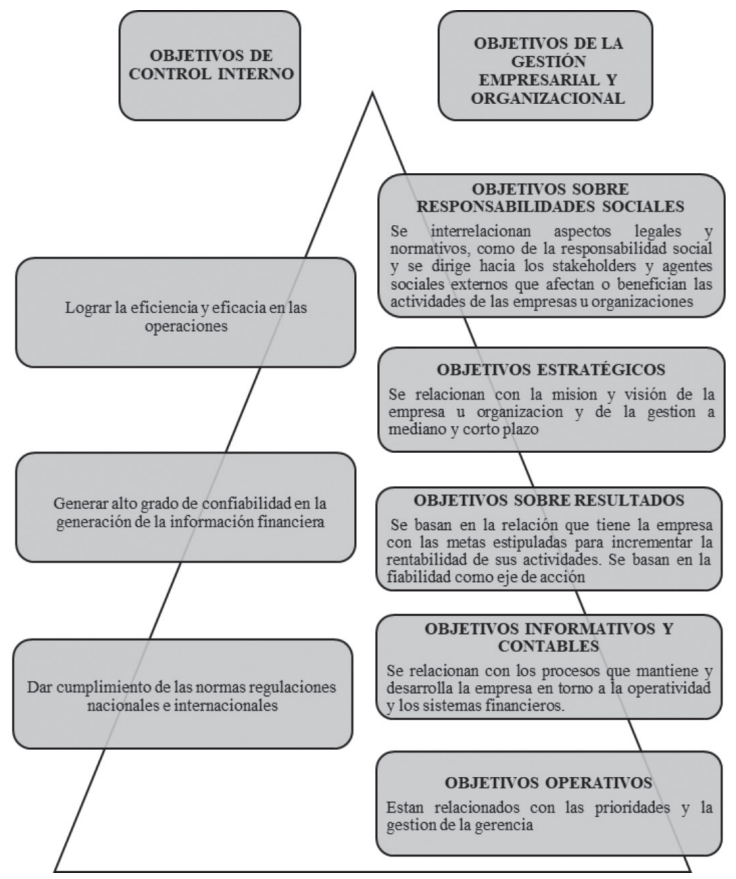

Fuente: Adaptado de Eslava, 2013; Vásquez, 2016.

Tabla 1. Componentes del control interno

\begin{tabular}{|c|c|}
\hline $\begin{array}{l}\text { Ambiente } \\
\text { de control }\end{array}$ & $\begin{array}{c}\text { Hace referencia a esa cultura de conciencia por el control de sus empleados y de } \\
\text { las actividades que desarrollan. }\end{array}$ \\
\hline $\begin{array}{l}\text { Evaluación } \\
\text { de los riesgos }\end{array}$ & $\begin{array}{c}\text { Consiste en la identificación y análisis de los riesgos para determinar cómo se } \\
\text { deben administrar. }\end{array}$ \\
\hline $\begin{array}{l}\text { Actividades } \\
\text { de control }\end{array}$ & $\begin{array}{l}\text { Actividades basadas en las políticas y procedimientos de control, en las que se } \\
\text { consideran diferentes factores específicos de la organización. }\end{array}$ \\
\hline $\begin{array}{l}\text { Actividades de } \\
\text { información y } \\
\text { comunicación }\end{array}$ & $\begin{array}{c}\text { Son herramientas estratégicas para la gestión de empresas, con funciones de } \\
\text { carácter estratégico y elementos de progreso y de eficacia en el marco de la vida } \\
\text { institucional. }\end{array}$ \\
\hline $\begin{array}{l}\text { Actividades de } \\
\text { monitoreo y seguimiento }\end{array}$ & $\begin{array}{l}\text { Se realizan por medio de evaluaciones de procesos o de resultados, busca } \\
\text { comprobar la efectividad y eficacia del proceso de ejecución de dichos controles. }\end{array}$ \\
\hline
\end{tabular}

Nota: Definiciones de los componentes del CI. Fuente: Adaptado de García, 2014; Vásquez, 2016.

\section{Modelos y estructuras de control interno}

COSO (Committe Of Sponsoring Organization Of The Tradeway): este modelo de CI tiene como finalidad realizar procesos de mitigación de los riesgos que cualquier tipo de empresa u organización afronta para lograr las metas definidas. Este modelo 
permite que el auditor diseñe una guía en la que la planeación y ejecución funge como un medio para un fin, no un fin en sí mismo (Moreno, 2017).

Modelo Estándar de Control Interno (MECI): este modelo permite que entidades estatales (en este caso, organizaciones colombianas) estructuren el CI en torno a estrategias de "gestión y evaluación, cuyo propósito es orientarlas hacia el cumplimiento de sus objetivos institucionales y la contribución de estos a los fines esenciales del Estado" (Cárdenas, 2012, p. 5). Este modelo se rige por los principios de autocontrol, autorregulación y autogestión.

COCO (Criteria of Control): "proporciona un marco de referencia a través de 20 criterios generales, que el personal en toda la organización puede usar para diseñar, desarrollar, modificar o evaluar el control" (Rivas, 2011, p. 126). Estos elementos se agrupan en cuatro criterios: objetivos por cumplir o cumplidos; compromisos realizados u obtenidos; aptitud; evaluación y aprendizaje del proceso realizado (Rivas, 2011).

COBIT: "Este modelo es muy utilizado para controlar y dar seguridad informática a las tecnologías de la información; utiliza servicios y soportes relacionados con la administración, el aseguramiento, entrenamientos y asistencia técnica" (Salnave y Lizarazo, 2017, p. 93).

CADBURY: este modelo de CI se enfoca en la gestión y control de los objetivos que se direccionan hacia la efectividad, eficiencia y confiabilidad de las operaciones y reportes financieros (Salnave y Lizarazo, 2017).

TURNBULL (Internal Control Guidance for Directors on the Combined Code-UK): este modelo de control procura brindar soporte a las entidades públicas, respecto a la atención de exigencias sobre CI, en el cual es "ficha clave para la administración de riesgos y para el logro de los objetivos" (Salnave y Lizarazo, 2017, p. 93).

\section{La auditoría ambiental como herramienta de control fiscal para la sostenibilidad}

La auditoría ambiental se ha implementado en Estados Unidos desde la década de 1960. Esto hizo parte de una reglamentación restrictiva a propósito de la utilización y explotación de la naturaleza de la región, con afectación ambiental (Marques y Marques, 2002). Lo cual se asocia con la sostenibilidad ambiental en el marco de la responsabilidad social de las organizaciones, siendo la protección ambiental y el desarrollo regional el fin.

"El objetivo primordial de la auditoría ambiental es la identificación, evaluación y control de los procesos industriales que puedan estar operando en condiciones de riesgo o provocando la contaminación del medio ambiente" (Marqués y Marques, 2002 , p. 44). En la que se comprueba, examina y evalúa la aplicación de las medidas de control y mitigación a los riesgos que provocan la producción empresarial e industrial, producto de las actividades realizadas hacia el medio ambiente (Escobar, 2009). 
La auditoría ambiental, como fundamentación, hace necesario generar procesos sostenibles y el CI; esto como eje de mitigación de los daños ya causados al medio ambiente y, por ende, a la sociedad a la que se dirigen las acciones por prevención, restauración y compensación de los impactos negativos (Escobar, 2009; Tamborino y González, 2018).

\section{La contabilidad ambiental - CA como herramienta de auditoría y control}

El desarrollo de una nación está ligado a las potencialidades y a los recursos particulares de la región, donde el suelo brinda las materias primas para la producción en el que se hacen necesarias diferentes habilidades por parte de los pobladores y sectores económicos, en las que se pongan en práctica herramientas para salvaguardar los bienes y recursos naturales, al igual que la reparación y mitigación de los daños causados al ambiente.

Se requiere entonces que la contabilidad ambiental sea una herramienta de organización y control de información en la administración y aprovechamiento de recursos ambientales, permitiendo que la gestión ambiental logra los objetivos planteados en su política bajo parámetros y lineamientos de sostenibilidad y desarrollo de las regiones (Verjel y Mantilla, 2012, p. 73).

Es así, como la CA figura como la herramienta de control y organización de la valoración cualitativa y cuantitativa sobre la preexistencia y circulación de los recursos naturales y ambientales de la nación y que son explotados por las diferentes organizaciones y empresas, en las que se hacen necesarias la implementación de distintos métodos y técnicas (Mejía y Vargas, 2012) “cuyo propósito es mostrar los resultados reales sobre manejo de recursos económicos aplicados a la naturaleza de la conservación; información que facilita la toma de decisiones en acciones presentes y futuras" (Verjel y Mantilla, 2012, p.73), con el fin de mejorar la calidad de vida de los grupos poblacionales.

\section{Análisis situacional del CI en la autoridad ambiental (CAR)}

Es importante evidenciar la situación actual sobre la gestión y control de los recursos financieros y la relevancia que estos tienen en torno a las políticas de sostenibilidad del país, es por esto por lo que se realizó un análisis situacional, en el que se toma como ejemplo la CDMB. Para la realización de dicho análisis situacional se efectuó una revisión documental de los informes de CI del 2017 y 2018, los informes pormenorizados de CI del 2019, los informes de CI contables del 2011, los estados financieros del 2018, el plan de acción 2016- 2019, los informes de gestión del 2018 y el documento de integración de los planes institucionales con vigencia al 2019. Una vez recolectada la información se hizo una entrevista con una funcionaria de la Contraloría General de la Nación (CGN) conocedora de los procesos por su experiencia en auditoría a esta institución, quien comentó aspectos básicos para tener en cuenta en la realización de los procesos de auditoría a las CAR, posterior a esto la funcionaria 
recomendó la revisión elaborada en el 2018 y publicada en el 2019 sobre la auditoría financiera independiente realizada a la CDMB.

Teniendo en cuenta estos documentos en conjunto con la información suministrada en el Manual del Sistema Integrado de Gestión y Control (SIGC), se obtuvo la siguiente información: en la provincia de Soto, ejerce funciones de control y gestión la CDMB, con jurisdicción en 13 municipios de Santander (Bucaramanga, Floridablanca. Piedecuesta, Rionegro, El Playón, California, Matanza, Charta, Tona, Girón, Suratá, Lebrija, Vetas). Su estructura orgánica se encarga de administrar y gestionar distintos procesos, como gestión del conocimiento ambiental, el ordenamiento y la planificación ambiental, la gestión integral de la oferta ambiental, la gestión del riesgo ambiental, la evaluación y control a la demanda ambiental y la cultura ciudadana en torno a temas ambientales (CDMB, 2015).

Figura 2. Estructura organizacional CDMB

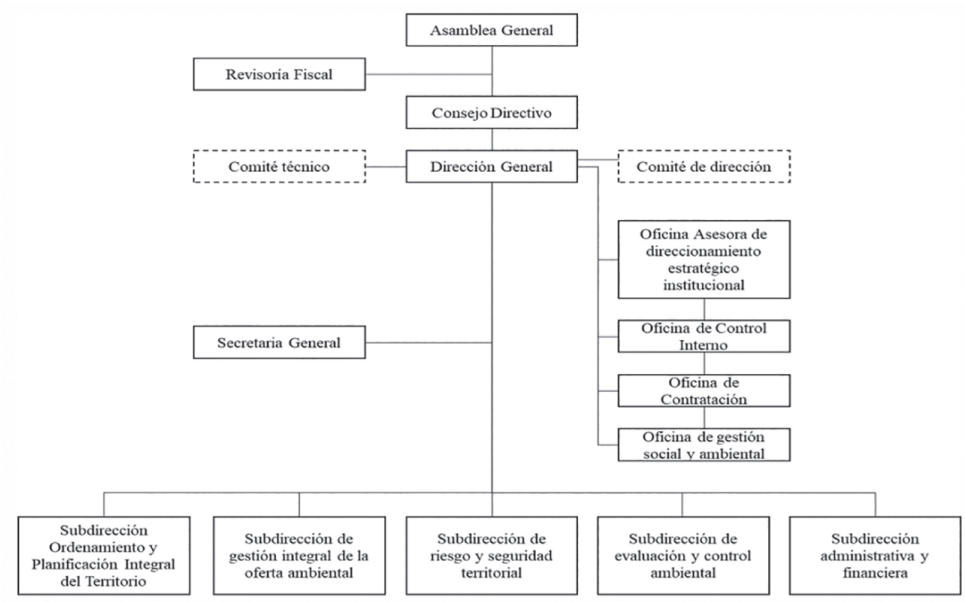

Fuente: CDMB, 2015

Coherente con el proceso misional y como parte de la gestión corporativa, la CDMB tiene como estructura de CI el modelo MECI, que se divide en dos módulos:

Planeación y gestión. De acuerdo con la metodología de PHVA (planear, hacer, verificar y actuar), la CDMB en conjunto con el director y el grupo líder del SIGC, articula actividades y tácticas del direccionamiento estratégico de la entidad, en las que se tienen en cuenta la actualización de planes de acción, según las seis líneas de acción estratégica (tabla 2) con vigencia al 2019; estas contienen, a su vez, acciones y objetivos que abarcan la población de Santander, en especial aquellos sectores productivos e industriales que generan daños en el ambiente, todo con el fin de lograr 
prácticas "de valor agregado que conduzcan a que el crecimiento sea sostenible ambiental, económica y social" (CDMB, 2018, p. 6).

La ejecución y medición de los indicadores se realiza con la retroalimentación que se efectúa periódicamente en la intranet del SIGC, respecto a la eficacia, eficiencia y efectividad de los procesos desarrollados, que dan como resultado un cumplimiento del 98,78\% de las metas propuestas en el 2018 (CDMB, 2019). En las políticas de operación, la CDMB recopila las principales políticas de funcionamiento y operación en una matriz en la que se tienen en cuenta los niveles de procesos y las líneas estratégicas (CDMB, 2019).

En relación con el talento humano, la $\mathrm{CDMB}$ propende la ejecución del plan institucional de capacitación, que tiene como base el plan estratégico del Ser, Saber, Hacer, adoptado mediante Resolución 0680 del 2018. En cuanto a la administración del riesgo, igualmente la CDMB actualiza en el transcurso del 2018 la FODA institucional mediante un taller con el fin de evidenciar riesgos en el proceso de gestión ambiental y de seguridad en el trabajo (CDMB, 2019; CDMB, 2018).

Evaluación y seguimiento. Para dar cumplimiento con la normatividad nacional respecto a la transparencia de los procesos, la CDMB realiza informes pormenorizados trimestrales en cuanto al CI de la entidad, al igual que el diligenciamiento del Formulario Único Reporte de Avance de la Gestión (FURAG). El grupo de SIGC, en conjunto con la Oficina de CI, hacen un seguimiento permanente al desempeño institucional, e informes sobre los planes de acción en proporción a los registros de mejoramiento continuo, además de los reportes al Sistema de Rendición Electrónica de la Cuenta e Informes (SIRECI), en vigencia con el 2018. En lo que respecta a las auditorías internas, la CDMB fomenta las acciones de procesos de gestión documental, cultura ambiental, gestión de las tecnologías de la información, gestión jurídica y las relaciones con las partes interesadas, en las que se ejecutan a través de las etapas de la planeación, ajuste de cronograma, ejecución, análisis, evaluación, seguimiento y evaluación pos-auditoría (CDMB, 2019).

Durante el transcurso del 2018, la CGR realizó un proceso de auditoría en el que se evidenciaron ocho hallazgos (deterioro de los activos, diferencia de la conciliación con cartera, baja de bienes, cartera coactiva, falta de revelaciones de los estados financieros, solicitudes de tasa por uso del agua, actuaciones a vertimientos puntuales por vertimientos de agua y operaciones reciprocas); teniendo en cuenta esto, la CDMB elaboró un plan de mejoramiento 2019 y lo registró en el SIRECI; en conjunto con estos hallazgos y con otros cuatro hallados en procesos institucionales, este Plan tiene 25 acciones encaminadas al mejoramiento de la CDMB como entidad ambiental de la región de Santander. Al 31 de diciembre del 2018 se reportó un cumplimiento del 89,8\% y un avance de 89,5\% de lo estipulado en el Plan de Mejoramiento (CDMB, 2019). 


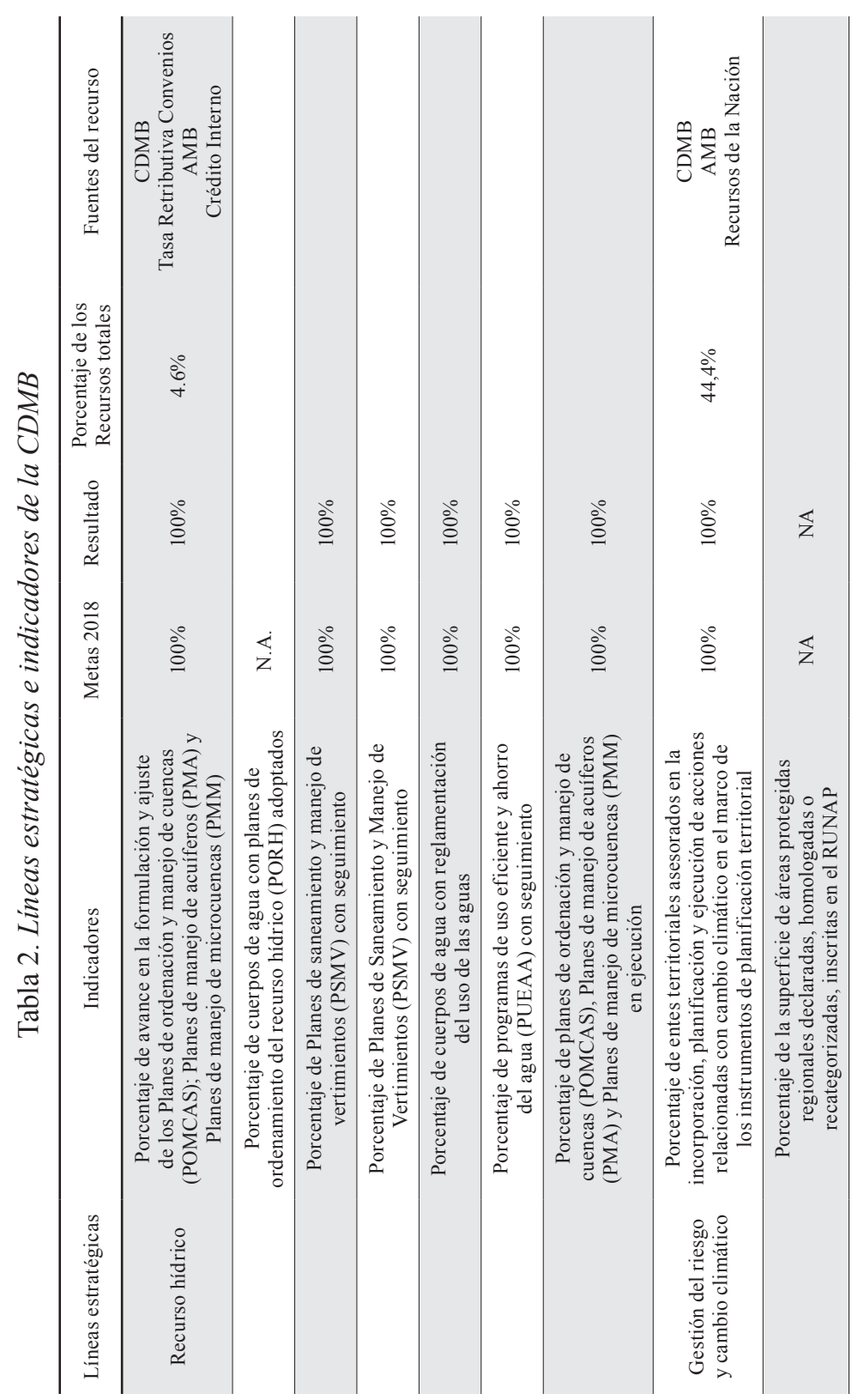




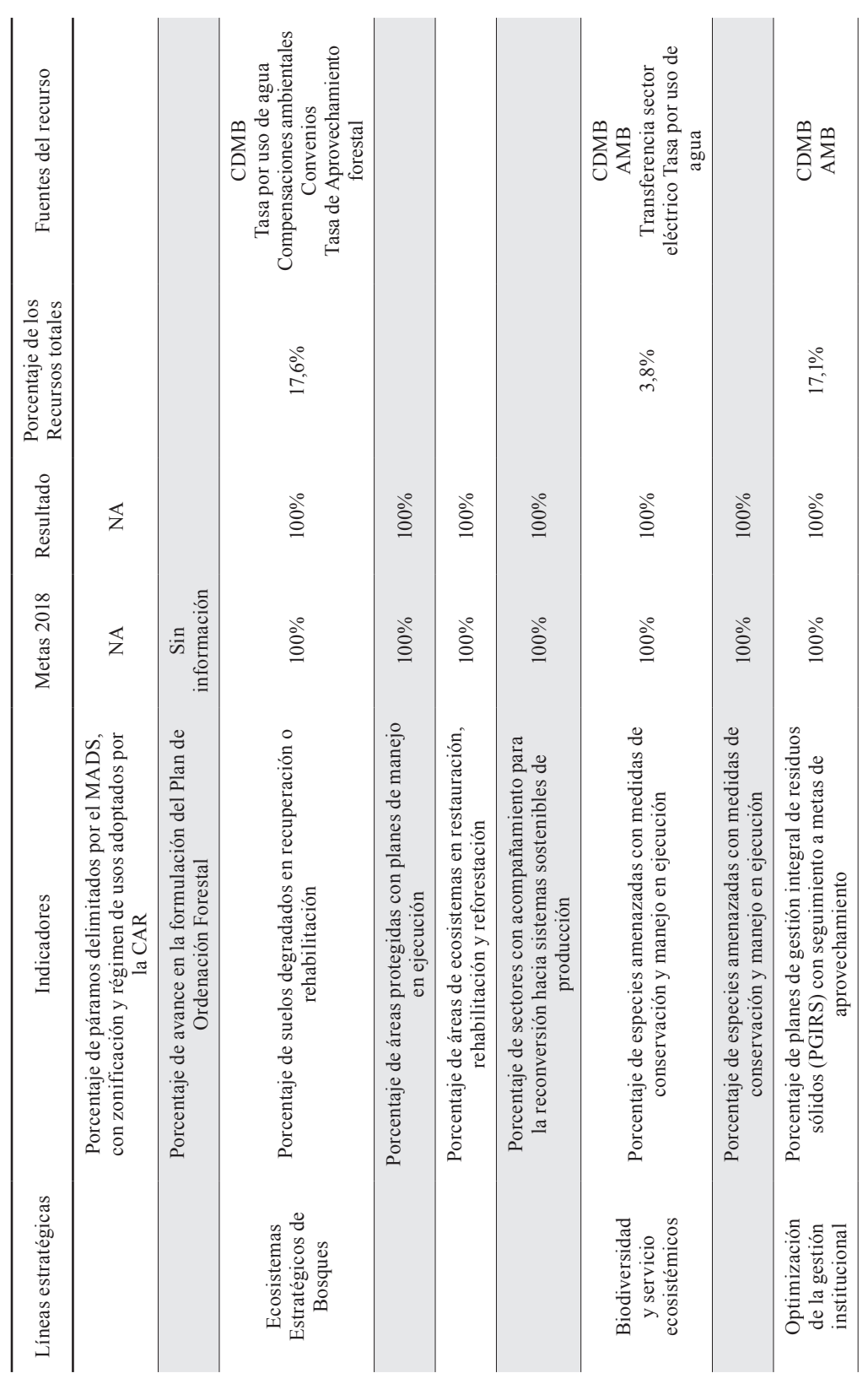



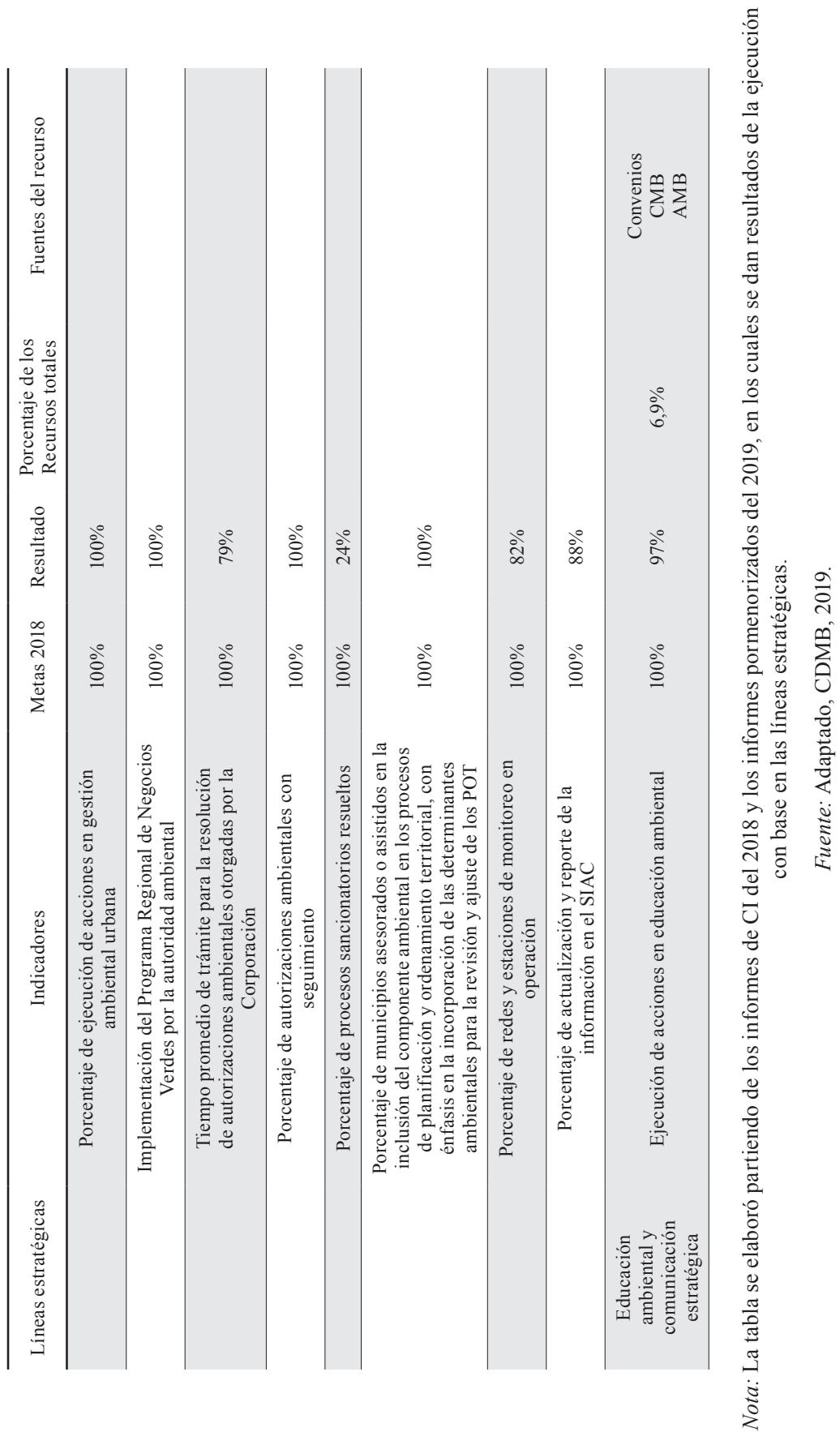
Con relación al Control Interno Contable, la información respecto a la evaluación de los procesos contables esta presentada en variables cuantitativas y cualitativas. Los resultados respecto a la evaluación cuantitativa registran una calificación de 4.85 de cinco (5) en la que se interpreta como Adecuado, en la que se resalta que los procesos contables se han desarrolla de manera idónea y según lo que está establecido por la CGR, además de que hay plena tipificación en los procesos de identificación y clasificación de la documentación contable (figura 3).

Parte del proceso de auditoría y CI, como debilidades, la CGR resalta que la CDMB no cuenta con una herramienta idónea que permita medir de manera eficaz la evaluación del MECI, igualmente no hay un ajuste de los indicadores en el que se implementen el uso de herramientas útiles en relación con las desviaciones de tiempo y el uso exacto de los recursos asignados sobre proyectos de índole ambiental. Por eso profieren la necesidad de, en primera medida, fortalecer los controles asociados en torno al grupo financiero y a la cultura de autocontrol, estipulada en el MECI (CDMB, 2018; CDMB, 2019; CDMB, 2011 CDMB y CGR, 2018; CGR, 2019). Sumado a lo anterior, no se han implementado sistemas de información que de manera georreferenciada evidencien los cambios en los activos y bienes ambientales, por lo cual muchos de los dineros destinados a gestión ambiental únicamente se evidencian como parte de la contabilidad financiera general.

En el Control Interno Financiero, con relación al diseño, efectividad, calidad y eficiencia de los controles presentó resultado con una calificación de 1,43, por lo cual se emite concepto Eficiente, en el que se resalta la inclusión de todos los pasivos, activos y patrimonios. Todos los hechos económicos que sucedieron en el transcurso del año gravable corresponden a los estamentos plasmados en los estados financieros, valorándose razonablemente, según es expuesto en la Resolución 489 del 2017. Finalmente, y como resultado del proceso de CI y de desempeño institucional del MECI, se obtiene un índice de madurez de 73,6 (Satisfactorio), desglosado de la siguiente manera: a) Ambiente de control - 71; b) Gestión del riesgo 73,3; c) Actividades de control 73,7; d) Información y comunicación 74,3 y e) Actividades de monitoreo 68 (CDMB, 2019).

Aunque la información proporcionada por la CDMB y la CGR estipulan un CI idóneo para los procesos administrativos, respecto al control y a la auditoría ambiental la ejecución se basa en metas poco medibles debido a que las tasas y sobretasas se fijan respecto a proyecciones nacionales y regionales que no tienen en cuenta el costo ambiental que generan los daños provocados, en el que no se establece una relación directa con la magnitud de los daños ambientales, económicos y sociales, causados por la contaminación en el territorio (CDMB y CGR, 2018; CGR, 2019).

Por ende, la captación de los tributos ambientales para remediar y mitigar las condiciones provocadas son de difícil proyección e implementación, debido a que los métodos de valoración que aproximen a datos relevantes sobre las condiciones ambientales son ineficientes, al igual que la valoración de los cambios ambientales 
en relación con los activos naturales de la región, en el que existe una clara pérdida en los conceptos técnicos emitidos desde la autoridad ambiental hacia los solicitantes de las licencias y proyectos ambientales.

Dado que no hay herramientas procedimentales para realizar un control y verificación de los procesos de contribución al daño al medio ambiente, las CAR, en especial la CDMB, no cuentan con un sistema contable ambiental georreferenciado, lo que conlleva que los resultados de la auditoría no reflejen la situación en relación con los flujos de dinero vinculado al manejo ambiental, y de esta manera visibilizar un mejor control y certeza de los aportes a la sostenibilidad ambiental.

\section{Cómo asegurar la sostenibilidad ambiental con recursos fiscales (a manera de estrategia)}

Para asegurar que los procesos en relación con la sostenibilidad y los recursos financieros se ejecuten de manera idónea, y que además correspondan con la situación actual del país y los fines en la constitución de las CAR, es necesario, en primer lugar, tener en cuenta la fijación efectiva de tasas retributivas, compensatorias y de uso, para lo cual no deben basarse simplemente en el valor de reposición o recuperación del activo natural, sino igualmente en los efectos ambientales, en la relación, naturaleza-hombre, su economía y su hábitat (Mantilla, Verjel y López, 2005), en el que se propenda por la participación de los diferentes entes públicos y privados, así como de la comunidad; además, de manera complementaria, que haya coherencia con la asignación presupuestal de las tasas e impuesto que se asignan a las CAR, en el que el monto que se fija y propone tenga una destinación que corresponda para lo cual fue diseñado e implementado. Esto permite no solo el adecuado manejo de los recursos, sino que también da la oportunidad de crear proyectos idóneos acorde con las necesidades de la población y la comunidad, aportando a la verdadera sostenibilidad socioambiental.

En segundo lugar, teniendo en cuenta las recomendaciones y explicaciones del funcionario de la CGR, se diseñaron dos flujogramas como herramientas básicas para el CI a los procesos de licencias ambientales y al establecimiento del cobro y destinación del recaudo de las tasas retributivas, como parte presupuestal de los programas ambientales en el que se recalca la necesidad de controlar actividades específicas de los procesos internos respecto a dichos procedimientos en la CDMB. Estas acciones son necesarias debido a que en las etapas de planificación de los programas ambientales se designan sobrecostos de los cuales no se evidencia la necesidad a la hora de ejecución de estos, igualmente hay riesgos en la emisión de los criterios y conceptos técnicos por parte de la CDMB.

Debido a que los procedimientos en las dos actividades establecidas como ejemplo del CI, si bien son soportados en los presupuestos de la CDMB de acuerdo con la normativa del Ministerio del Medioambiente y Desarrollo Sostenible y a estrategias 
administrativas de la corporación autónoma con el manejo de la contabilidad financiera, es posible evidenciar falencias en los sistemas de información por inexistencia de herramientas de registro y valoración de las condiciones ambientales y los cambios que se generen en los proyectos objeto de las licencias y en las bases de cálculo de las tasas retributivas, por lo que en los respectivos diagramas de flujo se evidencian alertas en este aspecto con triángulos rojos, pues aunque la CDMB esté fiscalizada por la CGR, esta situación es de riesgo alto para la pérdida de recursos fiscales y afectación de la sostenibilidad ambiental. En las siguientes figuras se observa los diagramas de flujo.

De acuerdo con el ente de control de las CAR -la CGR-si bien su responsabilidad es el buen manejo de los recursos fiscales de la nación, el no contar con una herramienta que permita revelar el asertivo cobro de las tasas y autorizaciones que afectan la naturaleza y el ambiente, impide una eficaz política de sostenibilidad, puesto que con la herramienta contable solo pueden evidenciar fuentes y usos de los dineros, mas no la justicia del cobro ni la eficacia y eficiencia de la destinación presupuestal en la conservación, mantenimiento y recuperación de los ecosistemas y la calidad ambiental.

De hecho, las corporaciones cuentan con un sistema de contabilidad financiera y manejo de presupuestos, así como banco de proyectos ambientales, pero no cuenta con un sistema de información contable ambiental que permita evidenciar las condiciones ambientales y los cambios en la naturaleza y los efectos en la sociedad, la economía y la misma naturaleza, como indicadores de sostenibilidad ambiental.

En efecto, en los diagramas de flujo presentados en páginas anteriores, se resaltan con triángulos rojos las actividades de riesgo, que en particular en el otorgamiento de licencias ambientales y establecimiento de estrategias de recuperación no se tienen bases que revelen realidades ambientales, ni métodos de medición y de valoración de los cambios ambientales (cambio en la naturaleza y sus efectos) que se originen con el proyecto que obtiene la licencia, como tampoco se cuenta con instrumentos para hacer seguimiento a los efectos del proyecto que obtiene la licencia, como se observa en el flujo del proceso de otorgamiento de licencia.

En el caso particular del cobro de tasas retributivas, si bien se habla de línea base de cargas o contaminación de las fuentes hídricas, los procedimientos de fijación de las bases de cálculo de las tasas por cobrar no provienen de métodos que aproximen a la realidad del daño que se causa por vertimiento, no obstante, fijarse un factor nacional establecido por el Ministerio de Ambiente y un factor adicional (opcional) fijado por la CDMB; factores que no corresponden al valor del daño causado, que es en la fuente hídrica vertida (recuperación de la fuente, efectos sociales y económicos por uso o contacto en la fuente contaminada) como exponen Mantilla, López y Verjel (2005). A esto se suma que la concepción de la autoridad ambiental sobre el cobro de la tasa retributiva corresponde al permiso que se otorga a las organizaciones para hacer sus vertimientos y no para recaudar y corregir el daño causado, como se supone que es el principio universal de la retribución: el que contamina paga y el dinero 


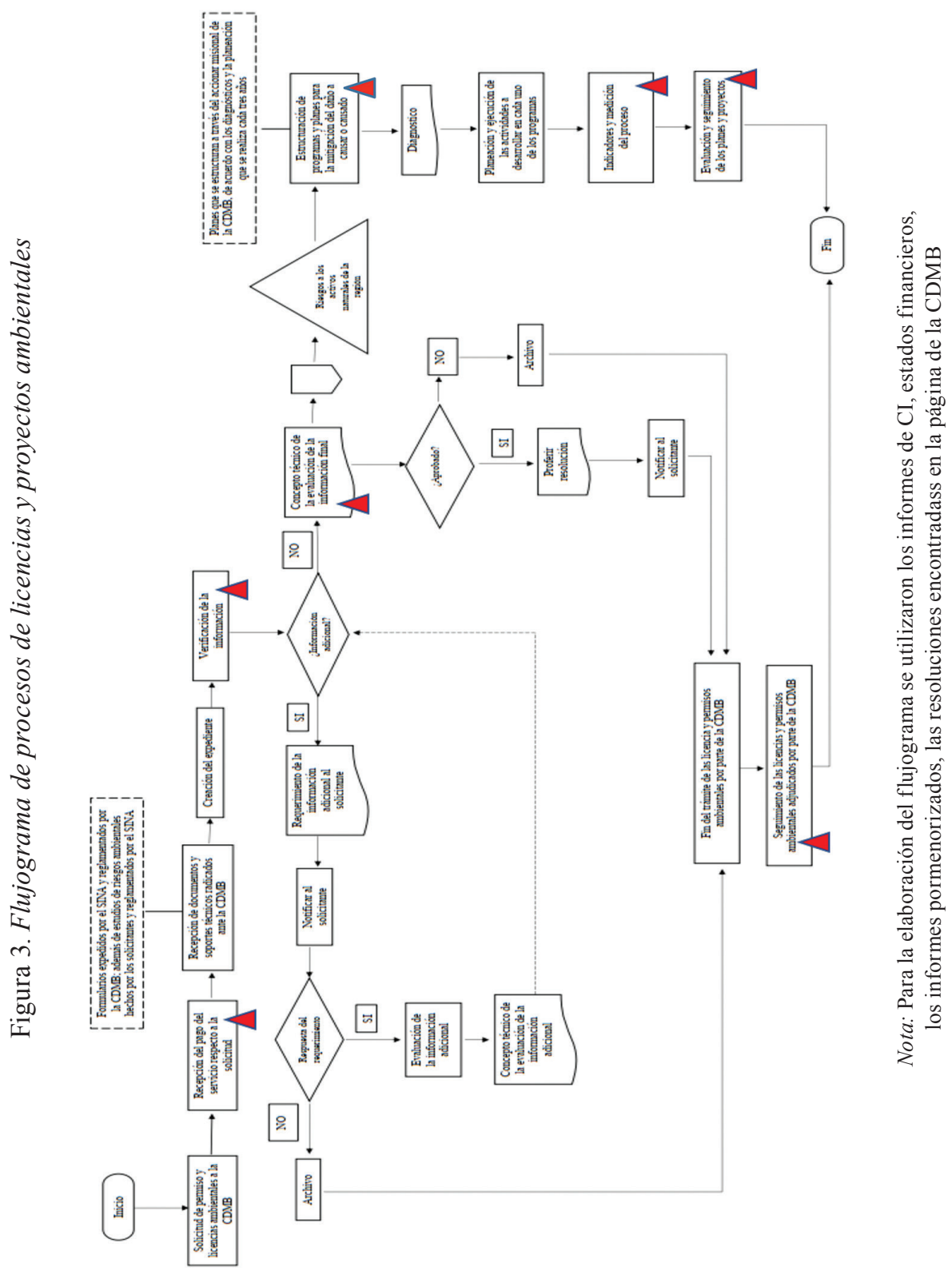



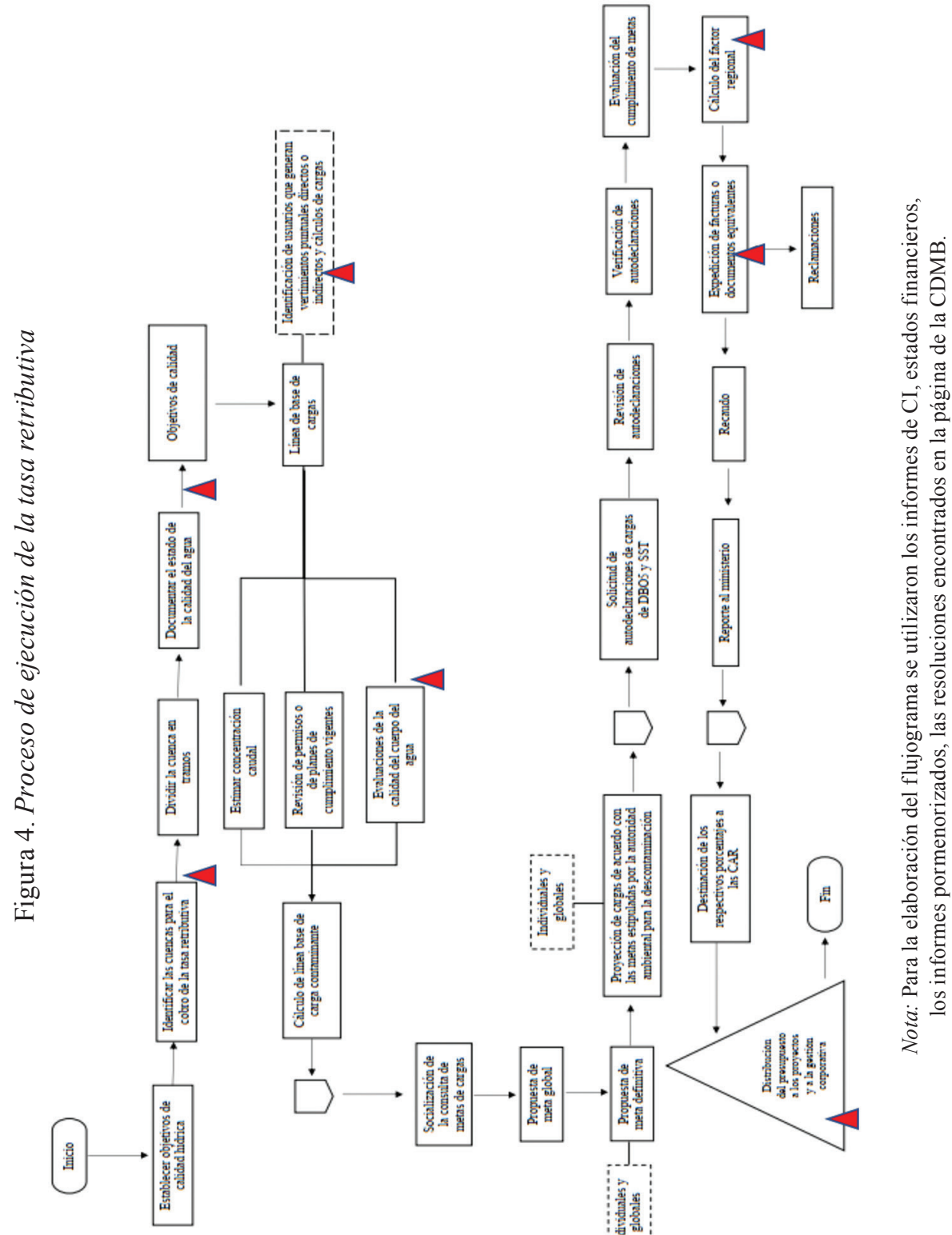
es para corregir el daño. De acuerdo con Mantilla (2005), el costo por contaminación hídrica se calcula con base en la alteración de la fuente que recibe el vertimiento y no solo por las características del agua vertida.

Figura 5. $\mathrm{Vca}=\mathrm{Cres}+\mathrm{Cex}$

\section{$\mathrm{V} c a=\mathrm{Cres}+\mathrm{Cex}$}

Vca: Valor de contaminación del agua; $\underline{\text { Cres: }}$ Costo de recuperación a estado seguro (Capital humano empleado en la descontaminación; Costo por uso de equipos y construcciones; Sustancias descontaminantes; Otros gastos del proceso); Cex: Costo de Externalidades (Costo por daño al hombre en consulta y tratamiento médico y costo cesante; Costo sobre el sector productivo por afectación de la agricultura y ganadería, o pérdida por incapacidad en el capital humano)

Nota: Fórmula para determinar el valor de la contaminación del agua.

Fuente: Adaptado de Mantilla, López y Verjel (2005, p. 78).

Esa situación obedece a la inexistencia de métodos apropiados de cálculo de las tasas y de una contabilidad ambiental que revele los efectos reales de la contaminación hídrica por los vertimientos de los actores sociales que los realizan. Por lo que en el diagrama de flujo se señalan las actividades de riesgo, por no disponer de métodos apropiados de valoración ambiental, ni un sistema de contabilidad ambiental georreferenciado.

Figura 6. Sistema de contabilidad ambiental

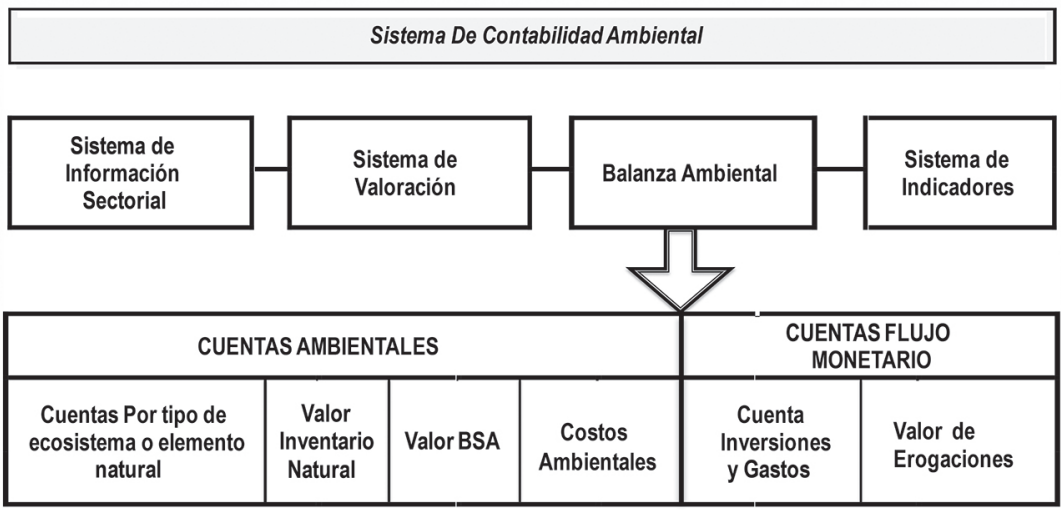

Nota: Esquema para la implementación de la contabilidad ambiental.

Fuente: Gómez y Mantilla (2018, p. 130).

De ahí que sea necesario contar con un sistema contable ambiental georreferenciado que permita a la CGR y a las CAR ejercer un control no solo financiero, sino 
físico de la gestión ambiental, con la verificación material de reposición, recuperación o conservación ambiental, por medio de indicadores medibles y valoraciones que aproximen la realidad ambiental, lo cual es esencial en la evaluación de la sostenibilidad ambiental.

\section{Conclusiones}

Las CAR como autoridades ambientales se encargan de velar por la recuperación y mitigación de los daños causados al medio ambiente por parte de los sectores productivos, por ende, estas deben propender soportar su actuar en herramientas eficientes que midan el correcto resarcimiento de los daños y la gestión corporativa. Para dicha labor es decisivo contar con mecanismos como el de control interno, que debe salvaguardar aquellos recursos públicos asignados. Sin embargo, estas, al no contar con un sistema exacto de medición, tienden a generar datos inexactos sobre supuestos que no valoran la realidad actual de los activos naturales de la región, creando procesos que no corresponden al costo ambiental que generan las actividades humanas y a que la asignación presupuestal para el resarcimiento de estas actividades no corresponda a lo que se le ha asignado por los organismos de control.

Por esto es improbable que los recursos fiscales que se designan a las CAR correspondan a un monto que evidencie la relación directa que genera la magnitud de los daños causados al ambiente, ya que el país no cuenta con las herramientas metodológicas que midan exactamente una valoración que se aproxime a la realidad de la naturaleza, el ambiente y la asignación de recursos fiscales, para esto es necesario un sistema de contabilidad ambiental georreferenciada que revele los activos naturales, en el que se fijen cifras reales de las tasas e impuestos, en los que se pueda asignar el adecuado uso de estos recursos fiscales. Al no tener una fijación exacta, respecto al valor de las tasas y de la medición de los daños, es difícil saber el alcance de la CDMB en torno al CI y la auditoría por parte de la CGR para determinar la calidad de la gestión fiscal para la sostenibilidad.

\section{Referencias}

Brenner, L. (2010). Gobernanza ambiental, actores sociales y conflictos en las áreas naturales protegidas mexicanas. Revista Mexicana de Sociología, 72(2), 283-310.

Cárdenas, J. (2012). Evaluación del impacto del modelo estándar de control interno (MECI) como herramienta de gestión para algunas entidades públicas de la ciudad de Palmira (tesis de maestría). Universidad Nacional de Colombia, Manizales, Colombia. Recuperado de https://core.ac.uk/download/pdf/11055566.pdf

Castromán, J., y Porto, N. (2005). Responsabilidad social y control interno. Revista Universo Contábil, 1(2),86-101. 
Contraloría General de la República. (CGR). (2019). Informe auditoría financiera independiente. Recuperado de https://www.contraloria.gov.co/documents /20181/1478524/005+Informe+Auditoria+Financiera+ANLA+v2018+ls.pdf

Corporación Autónoma Regional (CAR). (2018). Reseña histórica, La creación de la CAR: Ley 3a. de 1961. Recuperado de https://www.car.gov.co/vercontenido/2\#

Corporación Autónoma Regional para la Defensa de la Meseta de Bucaramanga (CDMB). (2011). Informe anual de evaluación del control interno contable. Recuperado de http://www.cdmb.gov.co/web/documentos/control-interno-1/713informe-control-interno-contable-2011-1/file

Corporación Autónoma Regional para la Defensa de la Meseta de Bucaramanga (CDMB). (2015). Manual del sistema integrado de gestión y control. Recuperado de http://www.cdmb.gov.co/web/ciudadano/centro-de-descargas/1310--40/ file $\#$ page $=3 \&$ zoom $=$ auto, 972,294

Corporación Autónoma Regional para la Defensa de la Meseta de Bucaramanga (CDMB). (2018). Informe de Gestión. Recuperado de http://www.cdmb.gov. $\mathrm{co} / \mathrm{web} / \mathrm{images} / \mathrm{Documentacion/gestion-institucional/informes-de-gestion/}$ informe $\% 20 \mathrm{de} \% 20$ gestion $\% 202018 \% 2025-02-2019$.pdf

Corporación Autónoma Regional para la Defensa de la Meseta de Bucaramanga (CDMB). (2018). Integración planes institucionales con el plan de acción 2016 -2019 “Unidos por el ambiente”. Recuperado de http://www.cdmb.gov.co/web/ documentos/gestion-institucional/ 1658--111/file

Corporación Autónoma Regional para la Defensa de la Meseta de Bucaramanga (CDMB) y Contraloría General de la República (CGR). (2018). Plan de mejoramiento institucional. Recuperado de http:/www.cdmb.gov.co/web/ images/Documentacion/gestion-institucional/ Plan\%20de\%20mejoramiento/ Nuevo\%20Plan\%20de\%20Mejoramiento\%20Institucional $\% 202019 \% 20 \mathrm{Vig} \% 20$ 2018(1).pdf

Corporación Autónoma Regional para la Defensa de la Meseta de Bucaramanga (CDMB). (2019). Informe pormenorizado del estado de control interno. Recuperado de http://www.cdmb.gov.co/web/images/Documentacion/gestioninstitucional/Control $\% 20$ interno/Informe $\% 20$ Porme norizado $\% 20$ C.I. $\% 20$ Marzo\%2012\%20de\%202019.pdf

Corporación Autónoma Regional para la Defensa de la Meseta de Bucaramanga (CDMB). (2019). Estados Financieros. Recuperado de http://www.cdmb.gov. co/web/images/Documentacion/gestion-institucional/informes-de-gestion/ estados\%20financieros\%20dic\%202018.pdf 
Correa, F., de la Ossa, A., y Vallejo, Z. (2007). Regulación ambiental en Colombia: el caso de la tasa retributiva para el control de la contaminación hídrica. Semestre Económico, 10(19), 27-46.

Corte Constitucional. (1993). Sentencia C-465 de 1993. Recuperado de https://www. funcionpubli ca.gov.co/eva/gestornormativo/norma.php?i=49848

De Castro, A., Cruz, J. L., y Ruiz, L. (2009). Educar con ética y valores ambientales para conservar la naturaleza. Convergencia, 16(50), 353-382.

Escobar, S. C. (2009). Realidad de los sistemas de gestión ambiental. Sotavento MBA (13), 68-79.

Eslava, J. (2013). La gestión del control de la empresa. Madrid, España: ESCIC Editorial.

García-Herrera, C., Torrejón, L., Alonso, D., y Del Blanco, Á. (2010). Estudio comparado de los sistemas tributarios en América Latina. Instituto de Estudios Fiscales, Ministerio de Economía y Hacienda. Recuperado de http://www.uca.edu. sv/mcp/media/archivo/dd91b6_estudiocomparadodelossistemastributariosenal.pdf

García, L. (2011). Teoría del desarrollo sostenible y legislación ambiental colombiana. Una reflexión cultural. Revista de Derecho, 20(20), 198-215.

García, M. (2014). El control interno como mecanismo de transformación y crecimiento, una mirada desde la gestión gerencial de las empresas. (Tesis de pregrado). Universidad Militar Nueva Granda, Bogotá, Colombia. Recuperado de https://repository.unimilitar.edu.co/bitstream/handle/10654/12715/ENSAYO\%20 -\%20OPCION\%20DE\%20GRADO\%20-\%20CONTROL\%20INTERNO. pdf? sequence $=1$

Giraldo, R. (2013). Apuntes acerca de los enfoques del derecho: una mirada más allá del tridimensionalismo. Revista Inciso, 15(1), 117-140.

Gómez, F., y Mantilla, E. (2018). Contabilidad y sostenibilidad ambiental en la empresa agropecuaria "Una aproximación a un caso de valoración de Activos Biológicos de la Hacienda Villa Isabela SAS”. In Vestigium Ire, 12(1), 118-144

Gudynas, E. (2009). Desarrollo sostenible: posturas contemporáneas y desafíos en la construcción del espacio urbano. Vivienda popular (18), 12-19.

Jaramillo, C., y Villa, M. (2003). La sobretasa ambiental al impuesto predial: Una propuesta de análisis desde la política ambiental y la hacienda pública. Ecos de Economía: A Latin American Journal of Applied Economics, 7(17), 109-129.

Lacouture, H. M. (2006). Aproximación a las autoridades ambientales regionales en Colombia. Revista de derecho: División de Ciencias Jurídicas de la Universidad del Norte (25), 308-334. 
López, E. (2012). Política fiscal y estrategia como factor de desarrollo de la mediana empresa comercial sinaloense. Un estudio de caso. México. (Tesis doctoral). Universidad Autónoma de Sinaloa, Sinaloa, México. Recuperado de http://acacia. org.mx/busqueda/pdf/18_PF226_Pol_tica_Fiscal.pdf

Luna, Y. (2017). El estado y el control fiscal del tributo ambiental frente a la sostenibilidad en el marco del desarrollo. (Tesis de pregrado). Universidad Santo Tomás Bucaramanga, Santander. Recuperado de https://repository.usta.edu.co/ handle/11634/4706

Mantilla, E., Cabeza, M., y Vargas, J. (2015). La realidad del desarrollo y la contabilidad ambiental. Saber, Ciencia y Libertad, 10(2), 133-143.

Mantilla, E., Vergel, C., y López, J. (2005). Medición de la sostenibilidad ambiental. Bogotá, Colombia: Editorial Universidad Cooperativa de Colombia Educc.

Mantilla, S. (2018). Auditoría del Control Interno. (4 ed.). Bogotá, Colombia: ECOE Ediciones.

Marques, J. J., y Marques, M. da C. (2002). Gestión medioambiental y auditoría. Contaduría y Administración, 205, 37-50.

Mejía, E., y Vargas, L. (2012). Contabilidad para la sostenibilidad ambiental y social. Lúmina, 13, 48-71.

Ministerio del Ambiente. (2004). Corporaciones Autónomas Regionales. Recuperado de http://www.minambiente.gov.co/index.php/component/content/article/885plantilla-areas-planeacion -y-seguimiento-33\#normatividad

Ministerio de Ambiente. (2014). Tasas por uso del agua. Recuperado de http://www. mina mbiente.gov.co/index.php/negocios-verdes-y-sostenibles/instrumentoseconomicos/tasa-por-utilizacion-de-agua

Ministerio de Ambiente. (2016). Tasa compensatoria por caza de fauna silvestre. Recuperado de http://www.minambiente.gov.co/index.php/negociosverdes-y-sostenibles/instrumentos-econ nomicos/tasa-compensatoria-poraprovechamiento-forestal-maderable

Molina, D., y Rivas E. (2017). Manual Políticas y Costos Ambientales. Recuperado de http://repository.udistrital.edu.co/bitstream/11349/6174/2/ MolinaVergelDanielOctavioAnexo-1.pdf

Moreno, Y. (2017). El COSO y su contribución a la toma de decisiones en la organización. (Tesis de especialización). Universidad Militar Nueva Granada, Bogotá, Colombia. Recuperado de https://repository.unimilitar. edu.co/bitstream/handle/10654/16139/MorenoYeseniaAngelica2017. pdf? sequence $=3 \&$ isAllowed $=y$ 
Muñoz, C. (2002). Financiación de la gestión ambiental en Colombia. El caso de las tasas. Revista de Derecho (18), 151-171.

Niño, J. (2017). Tributación ambiental en Colombia. (Tesis de pregrado). Universidad Militar Nueva Granada, Bogotá, Colombia. Recuperado de http://hdl.handle. net/10654/16090.

Rivas, G. (2011). Modelos contemporáneos de control interno. Fundamentos teóricos. Observatorio Laboral Revista Venezolana, 4(8), 115-136.

Rodríguez, K., y Ávila, V.(2014). Instrumentos de política pública para la conservación: su nacimiento y evolución en Colombia. Perfiles Latinoamericanos, 22(43), 127 158.

Salnave, M., y Lizarazo, J. (2017). El sistema de control interno en el Estado colombiano como instancia integradora de los sistemas de gestión y control para mejorar la eficacia y efectividad de la gestión pública a 2030. (Tesis de maestría). Universidad Externado de Colombia. Bogotá, Colombia. Recuperado de https:// bdigital.uexternado.edu.co/bitstream/001/661/1/ASA-Spa-2017-El_sistema de_control_interno_en_el_estado_colombiano_como_instancia_integradora_ Trabajo_de_grado.pdf

Tamborino, G., y González, J. (2008). Auditoría interna medioambiental basada en la gestión del riesgo corporativo: Un caso de estudio. Revista Universo Contábil, $4(2), 105-126$.

Vallaeys, F. (2012). Definir la responsabilidad social: una urgencia filosófica. Observatorio Regional de Responsabilidad Social para América Latina y el Caribe. ORSALC-UNESCO).

Vásquez, O. (2016). Visión integral del control interno. Contaduría Universidad de Antioquia, 69, 139-154.

Vélez, A. (2005). La información ambiental en Colombia. Gestión y Ambiente, 8(1), $85-94$.

Verjel, C., y Mantilla, E. (2012). La contabilidad ambiental en la planificación territorial. Bucaramanga, Colombia: Editorial El Libro Total.

Viloria, N. (2005). Factores que inciden en el sistema de control interno de una organización. Actualidad Contable Faces, 8(11), 87-92.

Viloria, J. R. (2010). Finanzas y gobierno de las corporaciones autónomas regionales del Caribe colombiano. Revista del Banco de la República, 83(996), 23-58.

Villegas, C., Castiblanco, C., Berrouet, L., Vidal, L. (2006). El programa de tasas retributivas en Colombia y el fortalecimiento institucional de las Corporaciones Autónomas Regionales. Gestión y Ambiente, 9(1), 7-24. 